University of Texas Rio Grande Valley

ScholarWorks @ UTRGV

Mechanical Engineering Faculty Publications

and Presentations

$12-14-2019$

\title{
Experimental study of condensation in a thermoacoustic cooler with various 3D printed regenerators using water vapor as the working fluid
}

\author{
Aibek Bekkulov \\ The University of Texas Rio Grande Valley, bekkulov@gmail.com \\ Andrew Luthen \\ The University of Texas Rio Grande Valley \\ Ben Xu \\ The University of Texas Rio Grande Valley, ben.xu@utrgv.edu
}

Follow this and additional works at: https://scholarworks.utrgv.edu/me_fac

Part of the Energy Systems Commons

\section{Recommended Citation}

Bekkulov, A., Luthen, A., and Xu, B. (December 14, 2019). "Experimental Study of Condensation in a Thermoacoustic Cooler With Various 3D-Printed Regenerators Using Water Vapor as the Working Fluid." ASME. J. Energy Resour. Technol. May 2020; 142(5): 050904. https://doi.org/10.1115/1.4045537

This Article is brought to you for free and open access by the College of Engineering and Computer Science at ScholarWorks@ UTRGV. It has been accepted for inclusion in Mechanical Engineering Faculty Publications and Presentations by an authorized administrator of ScholarWorks @ UTRGV. For more information, please contact justin.white@utrgv.edu,william.flores01@utrgv.edu. 


\title{
Experimental study of condensation in a thermoacoustic cooler with various 3D printed regenerators using water vapor as the working fluid
}

\author{
Aibek Bekkulov, Andrew Luthen, Ben Xu* \\ Department of Mechanical Engineering, The University of Texas Rio Grande Valley, Edinburg, TX, 78539, USA \\ *Corresponding author: Tel.: +1 (956)665-2896; Email: ben.xu@utrgv.edu (Ben Xu)
}

\begin{abstract}
Thermoacoustics (TA) deals with the conversion of heat into sound and vice versa. The device that transfers energy from a low temperature reservoir to a high temperature one by utilizing acoustic work is called TA cooler (TAC). The main components of a typical TAC are a resonator, a porous regenerator (e.g. stack of parallel plates) and two heat exchangers. The thermoacoustic phenomenon takes place in the regenerator where a nonzero temperature gradient is imposed, and interacts with the sound wave. The low temperature at the cold end of TAC can be used to condense water from the humid air and also reduce the moisture.

In the current study, the sound wave with high intensity was produced to drive a TAC to produce cooling power at a cold temperature around $18^{\circ} \mathrm{C}$, using saturated water vapor as the working fluid. The drainage of condensate in the regenerator is the key to the system's performance. This work is dedicated to investigate the effect from temperature gradient created in TAC on the condensation enhancement, by adopting three different designs of regenerators. 3D printer was used to design and fabricate different structures of regenerator, and then the systematic cooling capacity was tested and compared with different regenerators. This work can be extended to evaluate how the TA effect can be affected by the condensation if humid air is directly used as the working fluid. The potential application of this investigation can be an autonomous TAC system for water harvesting in arid areas.
\end{abstract}

Keywords: Thermoacoustics; Thermoacoustic cooler; Condensation; 3D printing.

\section{INTRODUCTION}

Thermoacoustic devices utilize acoustic waves to pump heat from one place to another or contrariwise creates an acoustic wave from the applied temperature gradient. One of the categories of such TA devices is thermoacoustic engine (TAE), which converts the heat to acoustic power, many applications about TAE can be found in the literature, such as cascade TAE [1], the heterogeneous porous stack in TAE [2], or small-scale $\alpha$-Type TAE [3]. One of the categories of such TA devices is thermoacoustic refrigerator (TAR), also called thermoacoustic cooler (TAC), where the acoustic power is used to pump heat from a low temperature source to a high temperature one [4]. TACs find their 
nice applications in various peculiar projects from small to medium scale experimental research cryogenic apparatuses to commercial gas liquefiers [5, 6].

TACs possess great advantages over traditional refrigeration technologies, such as the mechanical simplicity of construction, the usage of non-hazardous inert gases [7], no moving parts and high reliability coupled with minimum maintenance [8]. In addition, airborne moisture is a potential source of a plentiful amount of fresh water that is accessible everywhere and can be easily co-operated with a renewable energy source (solar energy). Recently, water harvesting from air shows a great promise in supplying water for community use in arid areas, portable water production by decentralized systems, and emergency water supply in post-disaster times [9]. Currently none of the existing commercial atmospheric water generators (AWGs) meets all the five criteria: efficient, cheap, scalable, wideband, and stable [9]. From the point of view of thermodynamics, this is mainly due to the energy inefficiency of the process, to the authors' best knowledge, most of the passive moisture harvesting processes are very difficult to control its thermodynamic efficiency [10], such as the fog water collection [11, 12], the dew water collection [13-15].

Therefore, it is expected that a system containing TAE that utilizes the heat from solar energy coupled with a TAC that utilizes the acoustic wave generated from TAE to create a temperature gradient (cold end side with a temperature close to saturation temperature), has a great potential to be used for autonomous atmospheric water harvesting in humid areas (such as south Texas and Florida), if the humid air is used as the working fluid, so that the water extraction process is more thermodynamic efficient and more controllable. In general, as shown in Fig. 1, TAC contains three main components: an acoustic speaker, a resonator tube filled with gas and a stack of plates along which, due to thermal interaction between oscillating gas undergoing compression/expansion cycles and the surface of the plates, the temperature gradient is created [16].

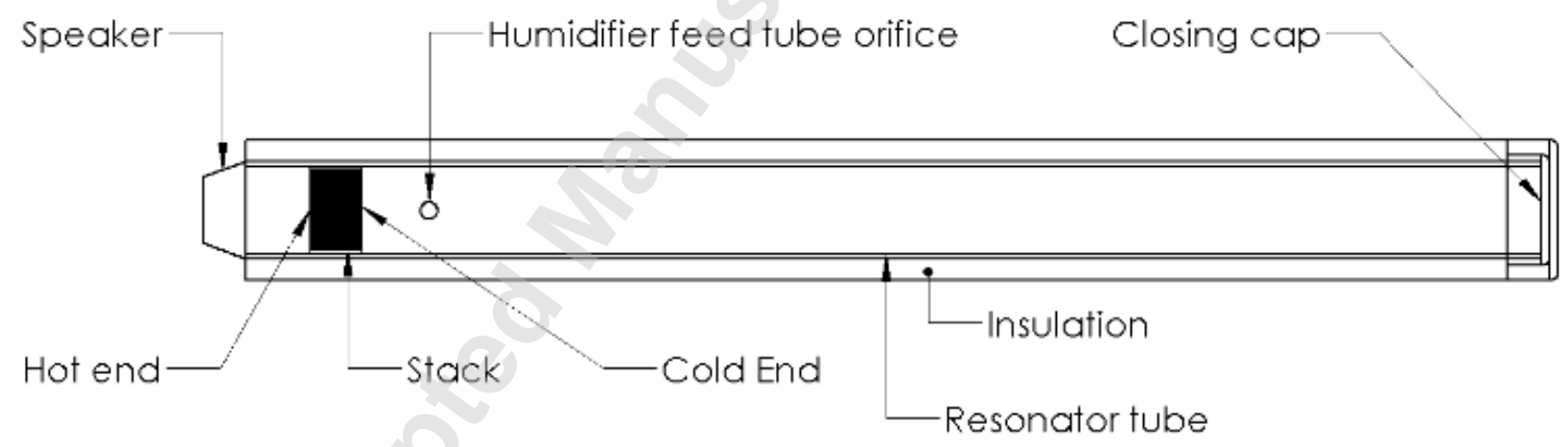

Fig. 1. Schematic of a general structure of TAR or TAC

However, in most of the practical application of TARs or TACs, the working fluid is Helium or Helium-Xeon [17]. If the working fluid is humid air and the cold end temperature reaches the saturation temperature, condensation will occur on the surface of stack in the TAC. Therefore, a dehumidification process may occur by condensing the water vapor when the condensed water flows along the stack plates. The flowing air stream exits the stack, and then the resonator, with a saturation temperature close to the temperature of the cold end of the stack [18]. To explore the effects of condensation on the thermoacoustic phenomenon, Hiller and Swift [19] developed two simple models, the 
wet-wall model and the fog model, to verify with an experiment of an open-flow thermoacoustic cooler with stack temperatures below the saturation temperature of the flowing air, and their results showed that the thermoacoustic effect of condensate droplets inside the stack is negligible.

However, if the incoming air has a high relative humidity level, there is a high chance that the condensate water droplet may block the air pathway, therefore the TA phenomenon may be affected. To assess the effects of extremely humid air, in this work the thermoacoustic refrigerator was built based on the design from Tijani et al. [20] with some modifications. The working fluid was chosen as the saturated water vapor generated from a humidifier. Consequently, the length of the resonator was specified to be half-wavelength TAC [21]. Such a standing wave pumps heat via counter-clockwise Brayton cycle [22] from the cold end of the stack to the hot end. Thermal insulation (mineral wool) was applied to the whole system to minimize the heat and sound losses. Furthermore, a small hole was drilled in the body of resonator to feed humid air from the lab into the system.

The entire project was divided into two stages: (1) design and build a working TAC; (2) conduct various sets of experiments to observe condensation in the TAC. For the second stage, a humid air was fed into a system and the mass of collected condensate in the end cap was measured, where the TAC was placed vertically to utilize the gravity for drainage. To verify the results, a reference TAC system without acoustic power input was built, with the same feeding humid air and saturated vapor from the same humidifier simultaneously, then the experimental results were compared.

\section{THE DESIGN OF TAC}

\subsection{General design strategy for TAC}

Fig. 1 illustrates the TAC built in this study. The source of acoustic wave was chosen to be generated from a car speaker connected with an amplifier, which has the following specifications in Table1, and the dimensions and air properties are listed in Table 2.

Table 1 Specifications of car speaker and amplifier

\begin{tabular}{lll}
\hline & Speaker & Amplifier \\
\hline Name & BOSS P45.4C & AOSHIKE \\
Max Power & $125 \mathrm{~W}$ RMS & $100 \mathrm{~W}$ (2 channels) \\
Nominal Impedance & $4 \Omega$ & - \\
Voltage & & $8-25 \mathrm{~V}$ \\
Frequency Response & $85 \mathrm{~Hz}-20 \mathrm{kHz} \pm 3 \mathrm{~dB}$ & - \\
Sound Pressure Level, SPL (1W/1m) & $83 \mathrm{~dB}$ & - \\
\hline
\end{tabular}

The resonator was build using a 5-ft long PVC pipe with 4" OD. Thus, knowing air properties in the lab, we could find the operating frequency to create a standing wave using the half-wavelength configuration.

$$
\text { Operating frequency, } f=0.5 \frac{\text { speed of air }}{\text { resonator length }}
$$

Table 2 Dimensions of resonator and air properties 


\begin{tabular}{ll}
\hline Parameter & Value \\
\hline PVC pipe (length) & $5 \mathrm{ft}(1.52 \mathrm{~m})$ \\
PVC pipe (diameter) & $4 "(0.10 \mathrm{~m})$ \\
PVC pipe (working temperature ranges) & $32-140 \mathrm{~F}\left(0-60^{\circ} \mathrm{C}\right)$ \\
PLA thermal conductivity $\left(k_{P L A}\right)$ & $0.13 \mathrm{~W} / \mathrm{m} \cdot \mathrm{K}$ \\
Lab air temperature & $22-23^{\circ} \mathrm{C}$ \\
Lab relative humidity $(\mathrm{RH})$ & $60 \%$ \\
Speed of air $\left(a_{\text {air }}\right)$ & 344 \\
Wavelength, $\lambda$ (half-wavelength, $0.5 \lambda)$ & $3.12 \mathrm{~m}(1.56 \mathrm{~m})$ \\
Angular velocity of sound wave $\left(\omega_{\text {wave }}\right)$ & $2 \pi f(691.15 \mathrm{rad} / \mathrm{s})$ \\
Thermal conductivity of air $\left(k_{\text {air }}\right)$ & $0.02624 \mathrm{~W} / \mathrm{m} \cdot \mathrm{K}$ \\
Air density $\left(\rho_{\text {air }}\right)$ & $1.2 \mathrm{~kg} / \mathrm{m}^{3}$ \\
Air dynamic viscosity $\left(\mu_{\text {air }}\right)$ & $0.000018 \mathrm{~Pa} \cdot \mathrm{s}$ \\
Isobaric specific heat capacity of air $\left(C_{p_{\text {air }}}\right)$ & $1010 \mathrm{~J} / \mathrm{kg} \cdot \mathrm{K}$ \\
Isochoric specific heat capacity of air $\left(C_{v_{\text {air }}}\right)$ & $718 \mathrm{~J} / \mathrm{kg} \cdot \mathrm{K}$ \\
Air heat capacity ratio $\left(\gamma_{\text {air }}\right)$ & 1.4 \\
Operating frequency $(f)$ & $110 \mathrm{~Hz}$ \\
\hline
\end{tabular}

There was a concern that the TAC was designed according to dry air properties, the humid air provided by the humidifier could drastically change the performance of the system. In general, at the same pressure humid air has a lower density than the dry air [23]. However, as the average operating temperature was assumed to be around ambient temperature in the lab, according to Fig. 2 [13], there is a negligible difference between the dry and humid air at such temperature. Therefore, it was safe to use dry air for the system design and operate it with both dry and humid air.

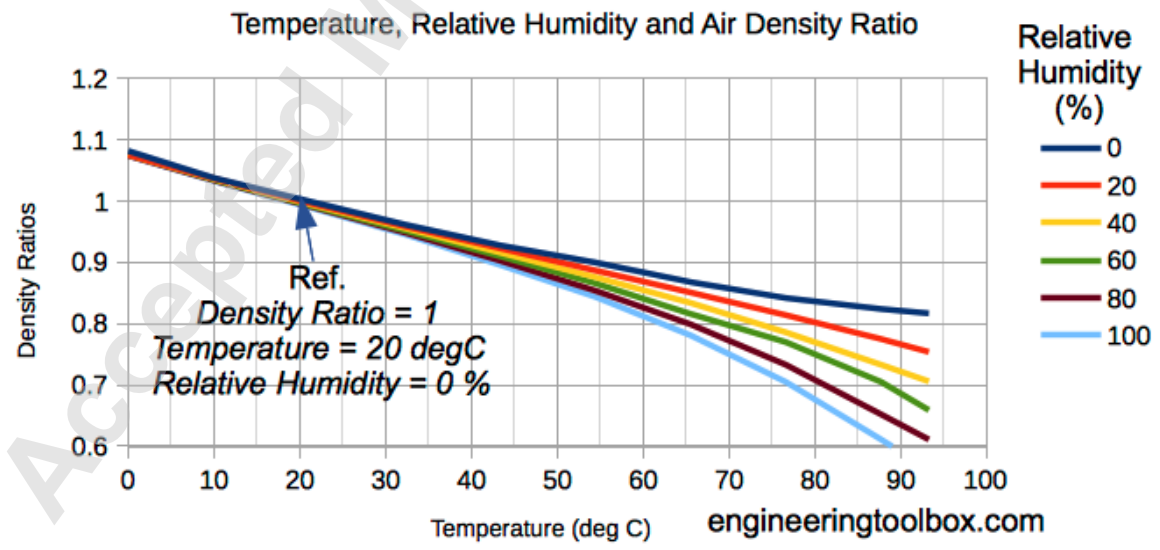

Fig. 2. Density of moist air at different temperatures with various relative humidity levels [13] 
It is important to notice that the operating frequency was recalculated using $113 \mathrm{~Hz}$ (theoretical) instead of 110 $\mathrm{Hz}$ (practical) after the system was assembled, and it appeared that the distance between the speaker and the bottom end cap was slightly bigger than the resonator itself due to the layer of adhesive material, which was used to connect the speaker and the resonator, in addition we need to count the thickness of end cap, as illustrated in Fig. 3.

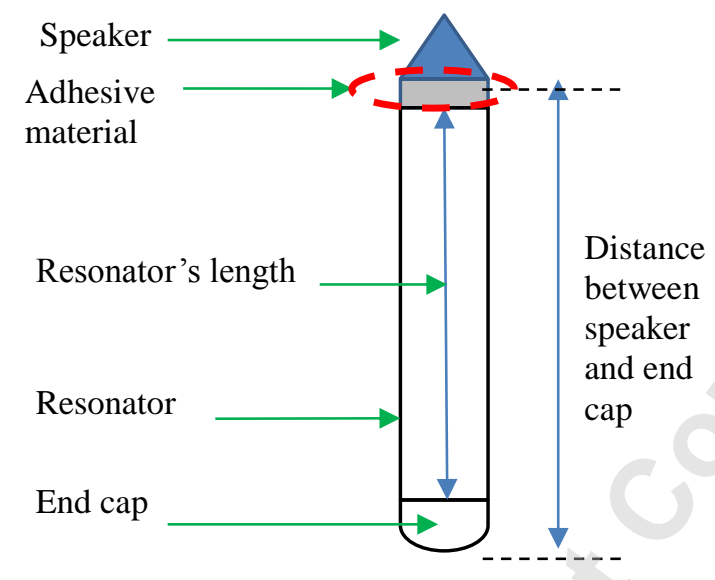

Fig. 3. Schematic of a TAC setup with adhesive material

The initial stack design consisted a number of parallel plates. The stack's position, length and the spacing between the plates were calculated using the boundary layer and short-stack approximation, as discussed in the work from Tijani et al. [20]:

- The acoustic field is assumed to not be disturbed by the presence of stack, since the stack's length is much smaller than the reduced acoustic wavelength.

- The Rott's functions can be simplified by assuming that the spacing between the parallel plates is greater than both the thermal penetration depth $\delta_{k}$ and the viscous penetration depth $\delta_{v}$.

- The gas properties inside the system are assumed to remain constant as the temperature changes are small.

Therefore, in order to choose the optimal length and position of the stack ( $L_{\text {stack }}$ and $x_{\text {stack }}$ respectively), the governing parameters were normalized. The position of stack represents a distance between the speaker and the center of stack, and it can be normalized with the length of stack ( $x_{s t a c k_{n}}$ and $L_{s t a c k}$ respectfully) via the wavenumber $(2 \pi / \lambda)$ :

$$
\begin{aligned}
& x_{\text {stack }_{n}}=x_{\text {stack }}\left(\frac{2 \pi}{\lambda}\right) \\
& L_{\text {stack }_{n}}=L_{\text {stack }}\left(\frac{2 \pi}{\lambda}\right)
\end{aligned}
$$

The spacing between parallel plates $\left(s s_{\text {stack }}\right)$ depends on the thermal penetration depth $\left(\delta_{k}\right)$. The other two important parameters are the viscous penetration depth $\left(\delta_{v}\right)$ and Prandtl number $(\operatorname{Pr})$.

$$
\begin{gathered}
\delta_{k}=\sqrt{\frac{2 k_{\text {air }}}{\rho_{\text {air }} C_{p_{\text {air }}} \omega_{\text {wave }}}} \\
\delta_{v}=\sqrt{\frac{2 \mu_{\text {air }}}{\rho_{\text {air }} \omega_{\text {wave }}}}
\end{gathered}
$$




$$
\operatorname{Pr}=\left(\frac{\delta_{v}}{\delta_{k}}\right)^{2}
$$

Typically, without affecting the acoustic field, the spacing between parallel plates needs to be between $2 \delta_{k}$ and $4 \delta_{k}$ [25]. For our stack, the spacing was selected as $3 \delta_{k}$.

$$
s s_{\text {stack }}=3 \delta_{k}
$$

The half spacing $\left(y_{0}\right)$ was adopted as the characteristic length to normalize the thermal penetration depth $\left(\delta_{k_{n}}\right)$.

$$
\begin{gathered}
y_{0}=0.5\left(s s_{\text {stack }}\right) \\
\delta_{k_{n}}=\frac{\delta_{k}}{y_{0}}
\end{gathered}
$$

Furthermore, each plate has a thickness $\left(t_{\text {plate }}\right)$ that depends on the material and manufacturing technique. We used 3D printer, which has $0.5 \mathrm{~mm}$ layer resolution, and PLA as the printing material, which has a low thermal conductivity to maintain the temperature gradient along the stack. Therefore, the blockage ratio $\left(B_{\text {stack }}\right)$ could be calculated as

$$
B_{\text {stack }}=\frac{y_{o}}{y_{0}+0.5 t_{\text {stack }}}
$$

All the calculated dimensions and geometries can be found in Table 3.

Table 3 Stack geometry and working gas (air) parameters

\begin{tabular}{ll}
\hline Parameter & Value \\
\hline Thermal penetration depth $\left(\delta_{k}\right)$ & $0.25 \mathrm{~mm}$ \\
Viscous penetration depth $\left(\delta_{v}\right)$ & $0.21 \mathrm{~mm}$ \\
Prandtl number $(\sigma)$ & 0.7 \\
Spacing between plates $\left(S S_{\text {stack }}\right)$ & $0.75 \mathrm{~mm}$ \\
Half spacing $\left(y_{0}\right)$ & $0.375 \mathrm{~mm}$ \\
Porosity of the stack $\left(B_{\text {stack }}\right)$ & 0.6 \\
Normalized thermal penetration depth $\left(\delta_{k_{n}}\right)$ & 0.667 \\
\hline
\end{tabular}

\subsection{Performance and optimization}

Two key pressures in the TAC are the mean pressure $\left(p_{m}\right)$ and the acoustic pressure $\left(p_{A}\right)$, and they play a vital role as they basically indicate the mechanical energy stored in the fluid [5] and thus directly correspond to the available acoustic power [26]. The ratio between them is called the drive ratio $(D)[20]$,

$$
D=\frac{p_{A}}{p_{m}}
$$

For this study, the mean pressure inside a resonator was assumed to be 1 bar as the air is not pressurized. Furthermore, the acoustic pressure was found via the acoustic Mach number (M) [20],

$$
p_{A}=M\left(\rho_{\text {air }}\right)\left(a_{\text {air }}\right)^{2}
$$

For gases, due to the nonlinear effects, acoustic Mach number is limited and can be assumed to be 0.1 .

Because the TAC in the experiment was designed to operate with unpressurized air as the working gas, the temperature gradient and temperature drop on the cold end of the stack were not expected to be great. Therefore, the 
temperature difference $\left(\Delta T_{m}\right)$ of 10 degrees between hot and cold end was expected to be reasonably good. Considering that the room temperature was around $23^{\circ} \mathrm{C}(296 \mathrm{~K})$, in the designing stage, we assumed $290 \mathrm{~K}$ on the cold end $\left(T_{c}\right)$ and $300 \mathrm{~K}$ on the hot end $\left(T_{h}\right)$. Correspondingly, the mean temperature $\left(T_{m}\right)$ along the stack should be something close to $295 \mathrm{~K}$.

$$
\begin{gathered}
\Delta T_{m}=T_{h}-T_{c} \\
T_{m}=\frac{T_{h}+T_{c}}{2}
\end{gathered}
$$

The temperature difference can also be normalized via the mean temperature.

$$
\Delta T_{m_{n}}=\frac{\Delta T_{m}}{T_{m}}
$$

Table 4 Design operating parameters

\begin{tabular}{ll}
\hline Parameter & Value \\
\hline Mean pressure $\left(p_{m}\right)$ & $1 \mathrm{bar}$ \\
Acoustic pressure $\left(p_{A}\right)$ & $0.14 \mathrm{bar}$ \\
Acoustic Mach number $(M)$ & 0.1 \\
Drive ratio $(D)$ & 0.141 \\
Stack's hot end temperature $\left(T_{h}\right)$ & $300 \mathrm{~K}\left(27^{\circ} \mathrm{C}\right)$ \\
Stack's cold end temperature $\left(T_{c}\right)$ & $290 \mathrm{~K}\left(17^{\circ} \mathrm{C}\right)$ \\
Mean temperature along the stack $\left(T_{m}\right)$ & $295 \mathrm{~K}\left(22^{\circ} \mathrm{C}\right)$ \\
Temperature difference $\left(\Delta T_{m}\right)$ & $10 \mathrm{~K}$ \\
Normalized temperature difference $\left(\Delta T_{m_{n}}\right)$ & 0.034 \\
\hline
\end{tabular}

In order to find the optimal stack's length and position, the COP can be calculated by considering different stack's lengths and positions, and the COP can be found as a ratio between the normalized heat flow $\left(Q_{n}\right)$ and the acoustic power $\left(W_{n}\right)[20]$.

$$
\begin{gathered}
Q_{n}=\frac{\delta_{k_{n}} D^{2} \sin 2 x_{n}}{8 \gamma_{\text {air }}(1+\sigma) \Lambda} \times\left(\frac{\Delta T_{m_{n}} \tan x_{n}}{\left(\gamma_{\text {air }}-1\right) B_{\text {stack }} L_{\text {stackn }}} \frac{1+\sqrt{\sigma}+\sigma}{1+\sqrt{\sigma}}-\left(1+\sqrt{\sigma}-\sqrt{\sigma} \delta_{k_{n}}\right)\right) \\
W_{n}=\frac{\delta_{k_{n} L_{\text {stackn }} D^{2}}}{4 \gamma_{\text {air }}}\left(\gamma_{\text {air }}-1\right) B_{\text {stack }} \cos ^{2} x_{n} \times\left(\frac{\Delta T_{m_{n}} \tan x_{n}}{\left(\gamma_{\text {air }}-1\right) B_{\text {stack }} L_{\text {stack }}(1+\sqrt{\sigma}) \Lambda}-1\right)-\frac{\delta_{k_{n}} L_{\text {stackn }} D^{2}}{4 \gamma_{\text {air }}}\left(\frac{\sqrt{\sigma} \sin ^{2} x_{n}}{B \Lambda}\right)
\end{gathered}
$$

where

$$
\begin{gathered}
\Lambda=1-\sqrt{\sigma} \delta_{k_{n}}+\frac{1}{2} \sigma \delta_{k_{n}}^{2} \\
C O P=\frac{Q_{n}}{W_{n}}
\end{gathered}
$$

Therefore, as most parameters were already defined, the COP could be represented as a function of stack's length and position. By plotting them in 3D, a set of length and position to achieve the peak COP can be found (thus optimizing length and position to achieve the best performance). 


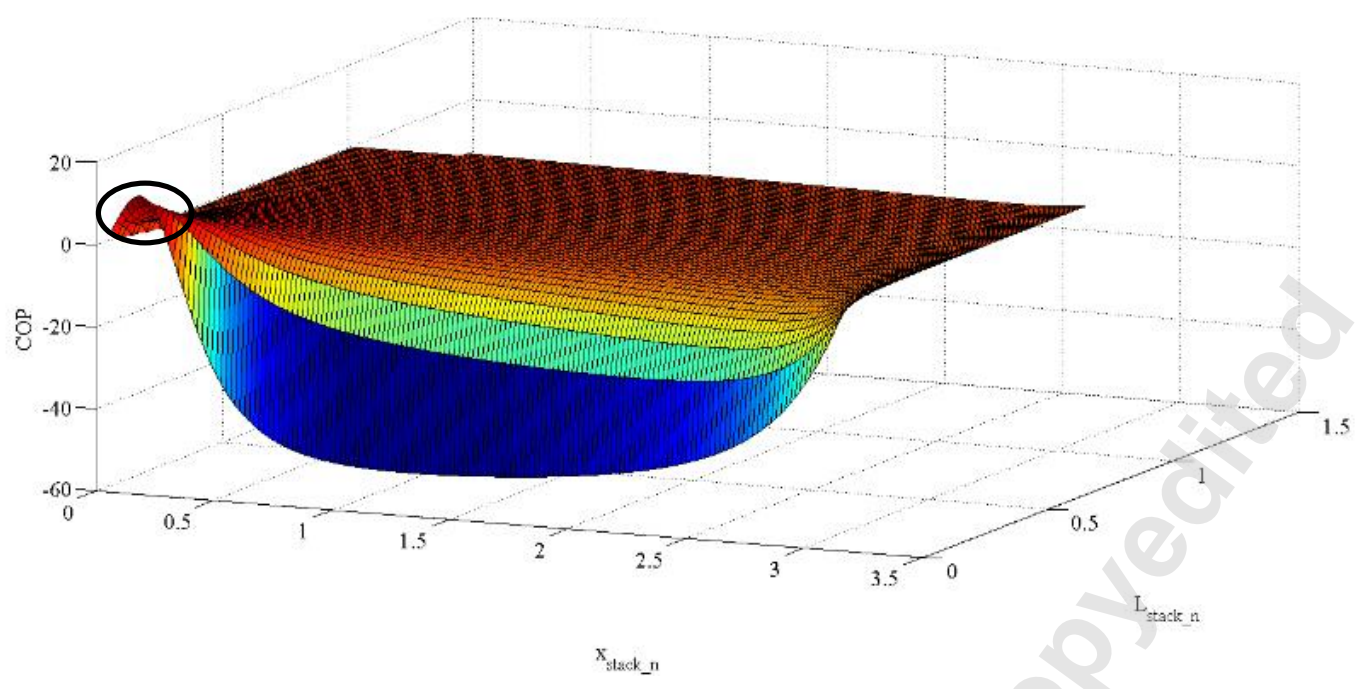

Fig 4. COP against normalized stack's length and position

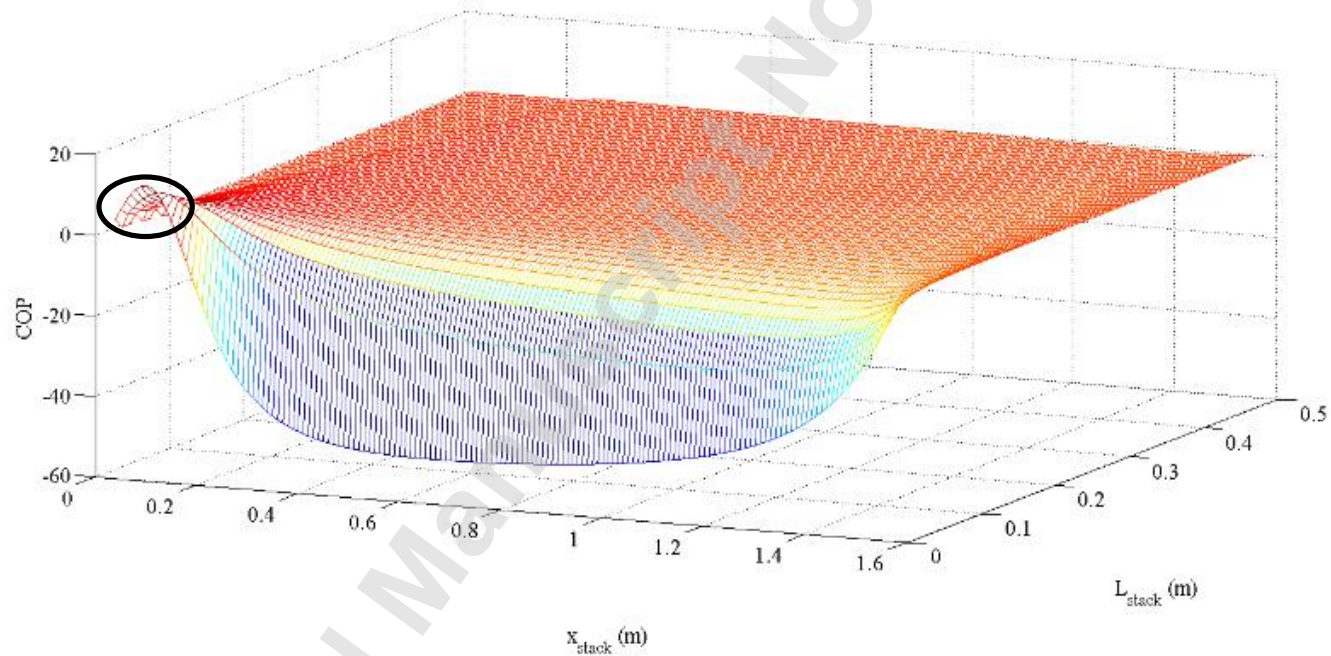

Fig. 5. COP against stack's length and position

The area marked by a black circle above the zero surface of COP in Figs. 4 and 5 represents the design window where the TA phenomena can take place, therefore the TAC needs to be designed within these areas. Obvisouly, shorter length and smaller position give higher COP (areas marked with green circle). However, the stack should not be too short as it would destroy the temperature gradient between the hot and cold ends due to the fast heat transfer via heat conduction. For the stack design in this study, $60 \mathrm{~mm}$ stack length and $75 \mathrm{~mm}$ stack position were chosen, and the corresponding theoretical COP is equal to 4.97 .

\section{EXPERIMENTAL SETUP}


As shown in Fig. 6, the whole experimental setup includes: (1) vertically standing TAC (covered with one-layer mineral wool insulation; (2) vertically standing reference system (same design as TAC, but without working TA effect); (3) water container (connected to hot end heat exchanger in the TAC as a heat sink) with water pump inside; (4) humidifier (alternately connected to TAC and to reference system with one end closed).

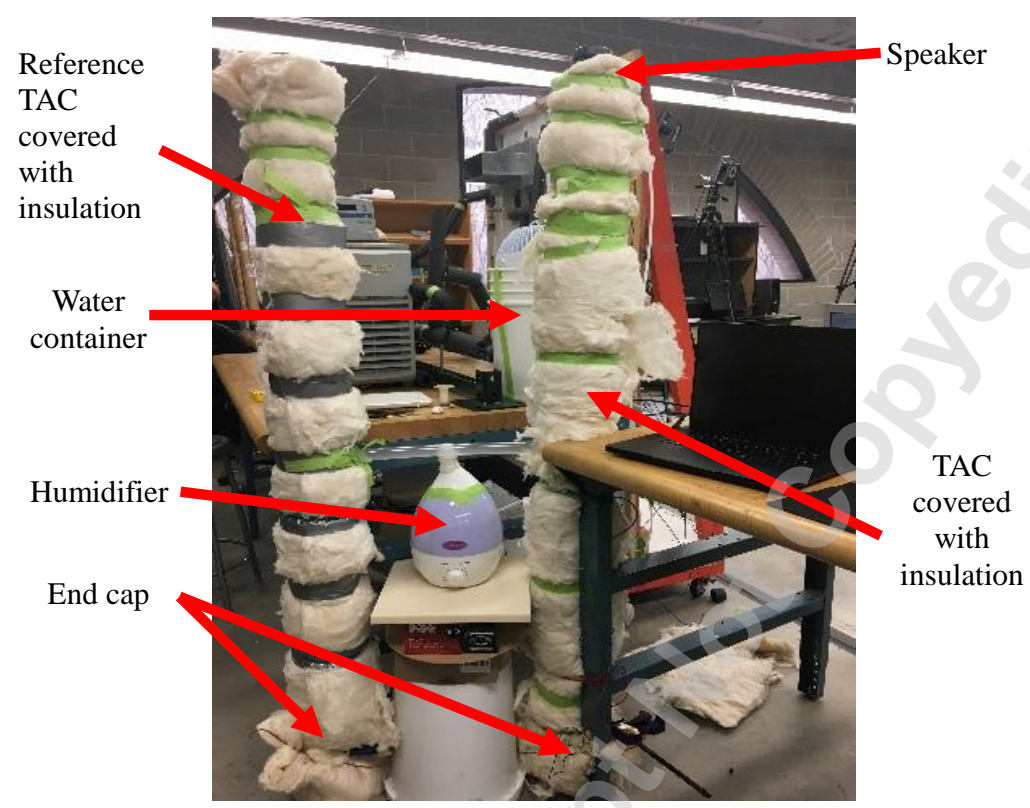

Fig. 6. Experimental setup of TAC and reference TAC without TA effect

The stack was 3D printed using PLA, which has thermal conductivity around $0.13 \mathrm{~W} / \mathrm{m} \cdot \mathrm{K}$. The copper heat exchanger was attached to the hot end of stack and connected through plastic pipes with the water bucket (heat sink), as demonstrated in Fig. 7. Generally, the copper heat exchanger was built to remove the excessive heat from the hot end (there were two heat sources: heat pumping from the cold end and the Joule heating from the speaker).

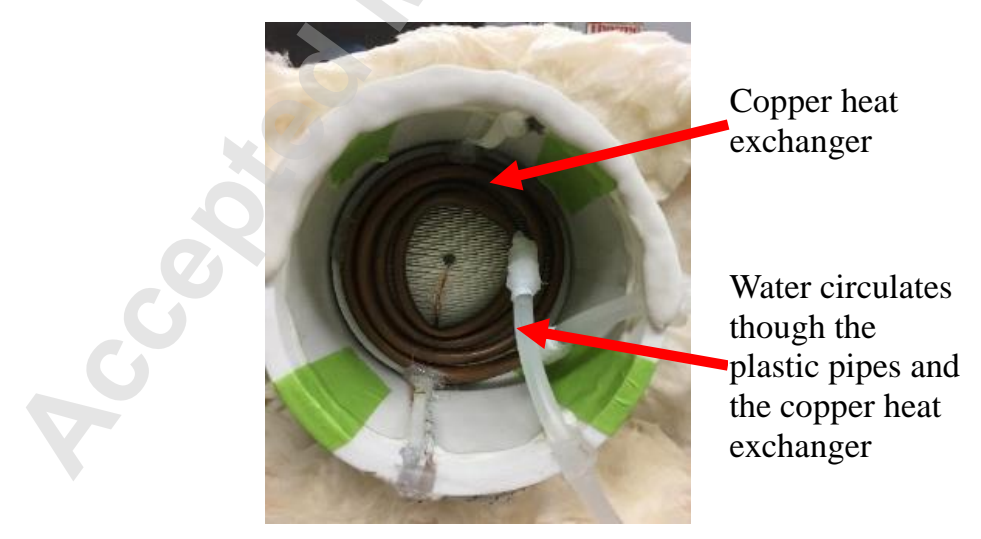

Fig. 7. Copper heat exchanger attached to the stack's hot end from TAC's top view 
To measure the temperature variation in the stack during the experiment, two T-type thermocouples were attached at the cold and hot ends of the stack, while another T-type thermocouple was submerged into the external water container to measure the temperature change once the heat was removed from the hot end. Humidifier was connected via a rigid transparent plastic tube to either the TAC or the reference system, and the connection was switched for each experimental run. The initial idea was to connect the humidifier to both systems simultaneously during the experiment. However, it was found that due to the higher pressure in the TAC when the speaker was on, the humidifier cannot equally feed the two systems. Therefore we decided to make two separated runs and connect the humidifier per experiment in order to obtain more accurate experimental results by ignoring the pressure effects.

In addition to the parallel plate stack, two more stack designs (squared mesh stack and circular plate stack) were 3D printed using PLA, so their performances can be compared. Therefore the three different stack designs can be found in Fig. 8.

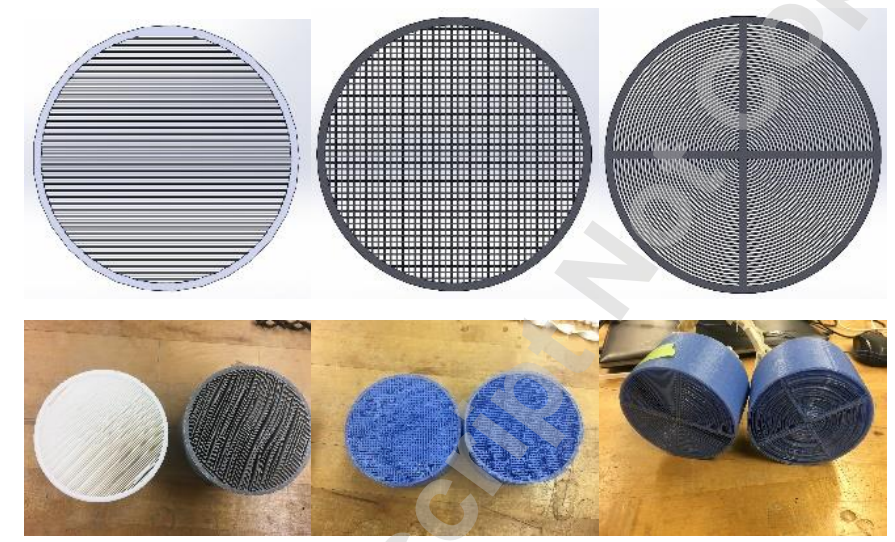

Fig. 8. CAD design (top) and 3D printed different design stacks (bottom). Parallel plates stack (bottom left), squared mesh stack (bottom middle), circular plates stack (bottom right)

The three stacks had the same outer diameter to fit the resonator $(100 \mathrm{~mm})$, the same length $(60 \mathrm{~mm})$, and were positioned $75 \mathrm{~mm}$ away from the speaker, according to the theoretical COP calculation. Consequently, they were designed to have the same theoretical blockage ratio as 0.6, but the CAD calculated blockage ratios were a little bit different from the theoretical values, as shown in Table 5.

Table 5 Three stacks' geometry and blockage ratio

\begin{tabular}{ccccc}
\hline Shape & Spacing $(\mathrm{mm})$ & $\begin{array}{c}\text { Solid surface area } \\
\left(\mathrm{mm}^{2}\right)\end{array}$ & $\begin{array}{c}\text { Theoretical blockage } \\
\text { ratio }\end{array}$ & CAD blockage ratio \\
\hline Parallel & 0.75 & 3661.93 & 0.6 & 0.53 \\
Square & 1.72 & 3688.31 & 0.6 & 0.53 \\
Circular & 0.75 & 3937.84 & 0.6 & 0.5 \\
\hline
\end{tabular}




\section{RESULTS AND DISCUSSIONS}

Three experimental sets with different stack designs were tested to obtain the temperature variations. The relative percentage of collected condensed water was also measured by measuring the weight of humidifier before and after the experiment to estimate how much water-vapor was fed, the weight of dry cap and wet cap before and after the test was also measured to estimate how much water was collected in the end cap.

Each experimental set had a preliminary experiment (Case 0) where TAC was running without connecting the humidifier to measure the maximum cooling performance using the humid air in the lab ( 50\% Relative Humidity). Then each set (Case 1-4) was tested with humidifier connected with both the TAC and reference systems. All the experimental cases can be found in Table 6, and the test protocol can be found as follows:

1) Humidifier and the dry end cap were separately put on the scales and their weights were measured before attaching to the TAC.

2) LabVIEW code was run to record the temperature variations at different locations.

3) The humidifier was turned on with the minimum flow.

4) The speaker was turned on ( $110 \mathrm{~Hz}$ working frequency sin wave audio signal) to initiate the TA effect in TAC.

5) After 1.5 hours, the humidifier and the speaker were turned off, the LabVIEW program was stopped and the thermocouples readings were saved. The bottom end cap was then removed so that the weight of wet cap together with water was measured on the scale (so the weight of collected water can be calculated). The humidifier was disconnected, and the weight of humidifier was measured (so the weight of loss water that was fed into the system can be calculated).

6) The humidifier and the dry end cap were weighted, and then connected to the reference system.

7) The humidifier was set to minimum flow again and another 1.5 hours experiment was started for the reference system (without thermocouples and speaker, therefore no TA phenomena).

8) After 1.5 hours, the humidifier was stopped and removed with the cap and they both were weighted again to measure the loss of water in the humidifier, and the weight of collected water in the end cap.

9) After each experimental set, both systems were dried for one day to ensure the water was completely dried.

Table 6 Experimental cases

\begin{tabular}{ccc}
\hline Case & Stack & Description \\
\hline P0 & Parallel plates & No humidifier \\
P1-4 & Parallel plates & Connected humidifier \\
S0 & Squared mesh & No humidifier \\
S1-4 & Squared mesh & Connected humidifier \\
C0 & Circular plates & No humidifier \\
C1-4 & Circular plates & Connected humidifier \\
\hline
\end{tabular}

The temperature variation versus time in the TAC for different cases are shown in Figs. 9-11 (all three figures share the same legend), and Table 7. T1 indicates a thermocouple attached to the hot end of stack, T2 implies a 
thermocouple attached to the cold end of stack and T3 is the thermocouple reading from the water container. Furthermore, the preliminary experiment data (Case P0, S0, $\mathrm{C} 0$ ) are marked with solid dark red curve (T1), solid dark blue curve (T2) and solid dark grey curve (T3), in order to make it visually be different from the experimental data when the humidifier was connected to the TAC (Case P1-4, S1-4, C1-4). In Table 7, there are four columns for initial and final temperatures at the hot end and cold end, respectively. Column "Max T2 drop" is for the maximum temperature drop from the initial temperature at the cold end, and column "Final T2 drop" column is for the temperature difference between the final and initial temperatures at the cold end. Column " $\%$ reduction" column represents the relative temperature decrease when compared to the reference value.

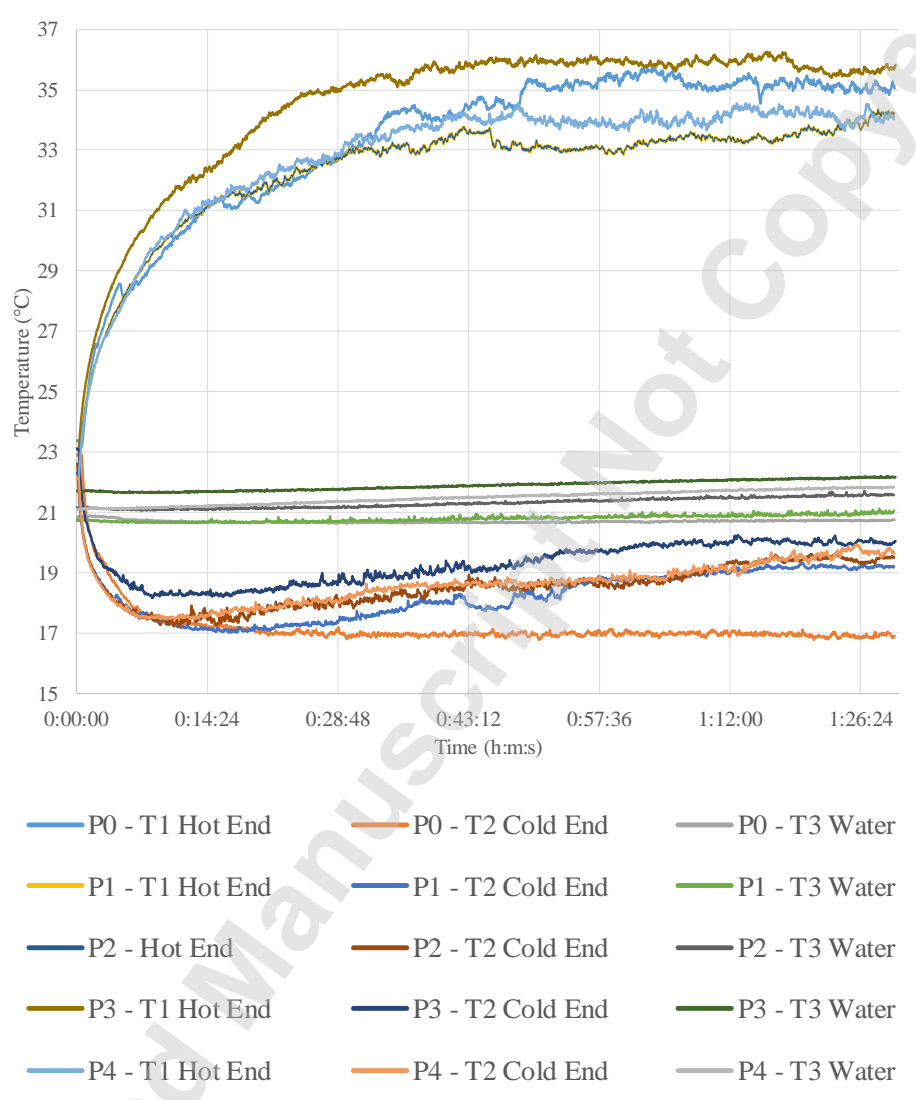

Fig. 9. Test results of parallel plates stack 


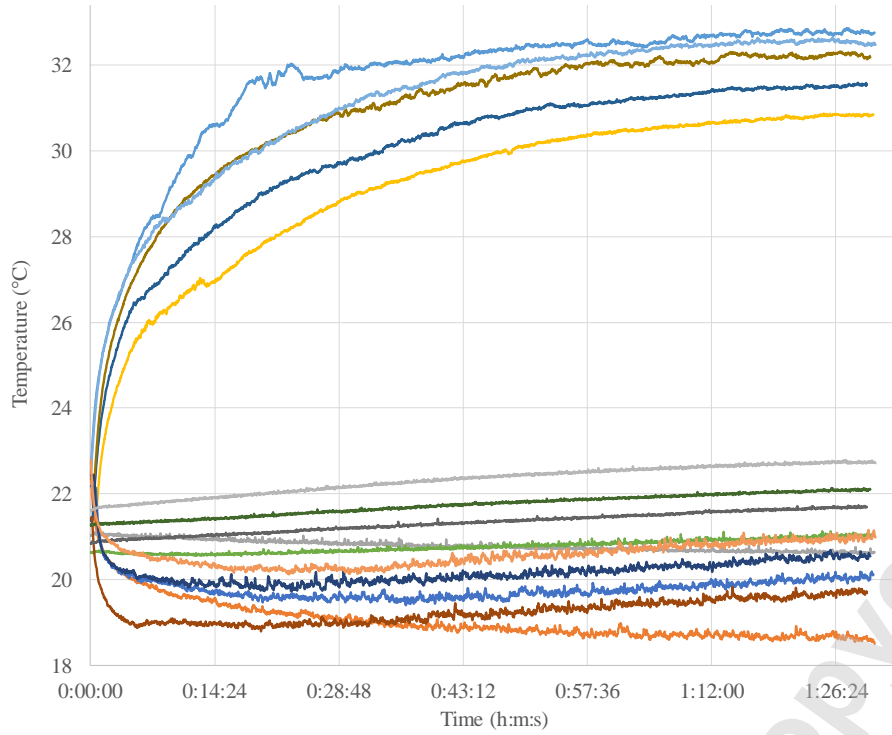

Fig. 10. Test results of squared mesh stack

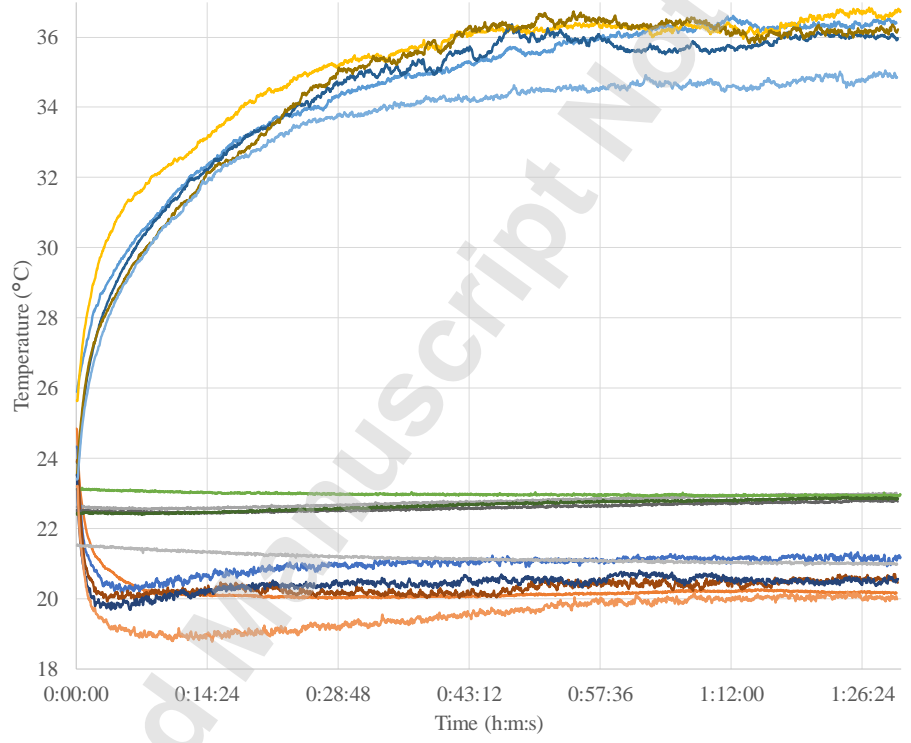

Fig. 11. Test results of circular plates stack

Table 7 Temperature readings for different cases

\begin{tabular}{cccccccc}
\hline$\#$ & $\begin{array}{c}\text { InitialT1 } \\
\left({ }^{\circ} \mathrm{C}\right)\end{array}$ & $\begin{array}{c}\text { Final T1 } \\
\left({ }^{\circ} \mathrm{C}\right)\end{array}$ & $\begin{array}{c}\text { Initial T2 } \\
\left({ }^{\circ} \mathrm{C}\right)\end{array}$ & $\begin{array}{c}\text { Final T2 } \\
\left({ }^{\circ} \mathrm{C}\right)\end{array}$ & $\begin{array}{c}\text { Max T2 drop } \\
\left({ }^{\circ} \mathrm{C}\right)\end{array}$ & $\begin{array}{c}\text { Final T2 drop } \\
\left({ }^{\circ} \mathrm{C}\right)\end{array}$ & $\%$ reduction \\
\hline P0 & 23.4 & 35.0 & 22.9 & 16.9 & 6.1 & 6.0 & Reference \\
P1 & 22.3 & 34.2 & 22.3 & 19.2 & 5.3 & 3.1 & 48.7 \\
P2 & 22.5 & 35.6 & 22.6 & 19.5 & 5.4 & 3.1 & 48.2 \\
P3 & 23.1 & 35.8 & 23.1 & 20.0 & 4.9 & 3.1 & 49.1 \\
P4 & 22.1 & 34.1 & 22.1 & 19.7 & 4.7 & 2.5 & 59.0 \\
\hline
\end{tabular}




\begin{tabular}{lllllllc}
\hline S0 & 22.5 & 32.8 & 22.8 & 18.5 & 4.3 & 4.3 & Reference \\
S1 & 21.6 & 30.8 & 22.2 & 20.1 & 2.8 & 2.1 & 51.5 \\
S2 & 21.4 & 31.5 & 21.4 & 19.7 & 2.6 & 1.7 & 59.0 \\
S3 & 22.4 & 32.2 & 22.4 & 20.5 & 2.7 & 1.9 & 55.6 \\
S4 & 22.6 & 32.5 & 22.8 & 21.0 & 2.7 & 1.8 & 57.8 \\
C0 & 25.9 & 36.4 & 24.8 & 20.2 & 4.8 & 4.7 & Reference \\
C1 & 25.6 & 36.5 & 24.3 & 21.1 & 4.2 & 3.3 & 30.1 \\
C2 & 23.9 & 36.0 & 23.9 & 20.5 & 4.0 & 3.4 & 26.3 \\
C3 & 23.5 & 36.2 & 23.5 & 20.6 & 3.8 & 3.0 & 36.9 \\
C4 & 23.4 & 34.9 & 23.2 & 20.0 & 4.4 & 3.2 & 31.3 \\
\hline
\end{tabular}

Table 7 can be used to evaluate the performance of TAC. There were some important observations from Table 7. First of all, TAC with parallel plates stack had the best cooling performance compared to other two designs. Secondly, the preliminary experiment without connecting to the humidifier showed a better performance in terms of maximum temperature drop at the cold end and large sustained final temperature gradient between the hot and cold ends. Thirdly, without a constant vapor input, TAC achieved the maximum temperature drop at the cold end, and the maximum temperature can be maintained for a relatively long period, as shown the solid dark blue lines in Figs. 9-11, so there is a negligible difference between "max T2 drop" and "final T2 drop" in Table 7. Nevertheless, when there was a constant vapor flow into TAC, the temperature at the cold end was significantly raised after max T2 drop point (light blue lines in Figs. 9-11). Moreover, if the final T2 drop for the Case-0 was taken as the reference value by assuming that all Case- 0 had the best TA performance, the relative reduction can be calculated for the cases and an average could be found. Such an average was important due to the following two reasons:

- It showed that the continuous vapor feeding damaged the TA performance (either the release of heat on the stack because of condensation or the condensate blocked the pores and simply decreased the blockage ratio).

- The different stack geometries could be quantitatively evaluated on the ability to resist such a damage to the TA phenomena from the enhanced condensation, for example the circular plate stack had the lowest relative reduction in T2 drop, and squared mesh stack had the largest relative reduction in T2 drop, therefore we can also conclude that the circular plates design was less affected by the damage to TA cooling from the condensation.

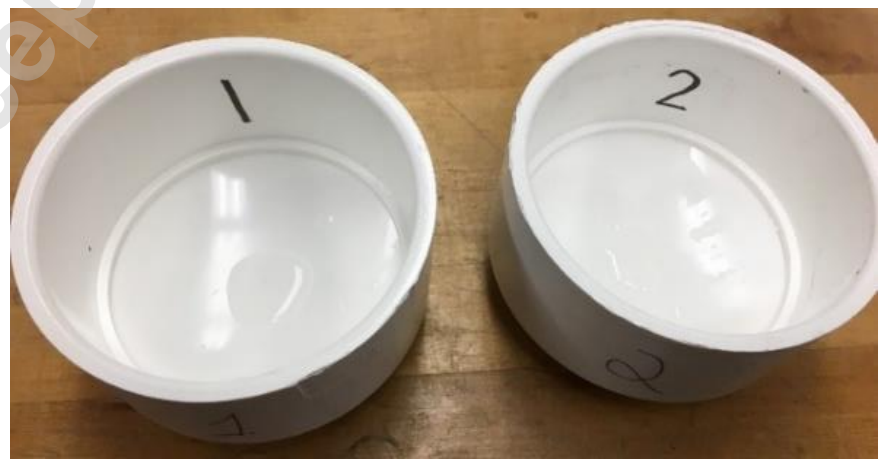


Fig. 12. Photo of harvested water in the end cap (left: from TAC; right: from the reference system)

Table 8 Harvested water for different experimental cases

\begin{tabular}{ccccccc}
\hline$\#$ & $\begin{array}{c}\text { Water fed into } \\
\text { TA }(\mathrm{g})\end{array}$ & $\begin{array}{c}\text { Water fed into } \\
\text { REF }(\mathrm{g})\end{array}$ & $\begin{array}{c}\text { TA cap collected } \\
\text { water }(\mathrm{g})\end{array}$ & $\begin{array}{c}\text { REF cap collected } \\
\text { water }(\mathrm{g})\end{array}$ & $\begin{array}{c}\text { Water collected in } \\
\text { TAC }(\%)\end{array}$ & $\begin{array}{c}\text { Water collected in } \\
\text { REF }(\%)\end{array}$ \\
\hline P1 & 12.2 & 12.6 & 6.8 & 6.3 & 55.7 & 50.0 \\
P2 & 18.2 & 17.8 & 10.4 & 6.2 & 57.1 & 34.8 \\
P3 & 11.0 & 18.0 & 4.3 & 6.3 & 39.1 & 35.0 \\
P4 & 18.1 & 26.4 & 6.7 & 6.5 & 37.0 & 24.6 \\
S1 & 36.4 & 37.1 & 18.4 & 16.0 & 50.5 & 43.1 \\
S2 & 28.2 & 29.8 & 13.1 & 13.3 & 46.5 & 44.6 \\
S3 & 35.3 & 29.7 & 21.6 & 9.3 & 61.2 & 31.3 \\
S4 & 41.8 & 22.8 & 22.1 & 6.8 & 52.9 & 29.8 \\
C1 & 28.1 & 24.4 & 19.2 & 8.6 & 68.3 & 35.2 \\
C2 & 21.1 & 20.5 & 10.0 & 8.6 & 47.4 & 42.0 \\
C3 & 12.5 & 20.1 & 6.2 & 7.4 & 49.6 & 36.8 \\
C4 & 35.5 & 18.1 & 19.8 & 5.8 & 55.8 & 32.0 \\
\hline
\end{tabular}

The next step was to measure the water consumed by the humidifier and the water harvested by the closing end cap in two systems as shown in Fig. 12 as an example for the collected water in the end cap. Table 8 shows the weight of harvested water for different cases. "Water fed" was calculated as the weight difference of the humidifier before and after the experiment. "Cap collected water" was measured before and after the experiment. "Water collected" was calculated as the percentage of collected water in the end cap and the water that was fed by the humidifier. To further illustrate the collected water and compare with different cases in TAC and reference system, Table 9 demonstrates the average percentage of the collected water for each stack design in both the TAC and the reference system. Two important observations can be concluded from Table 9 regarding the average percentage of collected water:

- The reference system had a percentage about $36 \%$ for the collected water, but the TAC reached a higher percentage, because the TA phenomenon enhanced the condensation and dehumidification.

- The difference of averaged percentage of collected water in the reference system was almost negligible, but the TAC varied a lot for different geometries, and the circular plates stack had the best water harvesting performance.

Table 9 Average water collected percentage

\begin{tabular}{ccc}
\hline Stack & Average water collected in TAC (\%) & Average Water collected in reference (\%) \\
\hline Parallel plates & 47.2 & 36.1 \\
Squared mesh & 52.8 & 37.2 \\
Circular plates & 55.3 & 36.5 \\
\hline
\end{tabular}


Furthermore, the water droplets on the stack's surface were also recorded using a camera, by inspecting the stack before and after the experiment. One example can be found in Fig. 13 for the parallel plate stack, the condensation in the reference system was equally dispersed on the parallel plates inside the stack, therefore a filmwise condensation was formed, but in the TAC system, the condensation was vastly concentrated on the bottom surface of the cold end of the stack, and a dropwise condensation was formed. This can also explain why the TAC had a better performance in terms of water harvesting, as shown in Table 9.
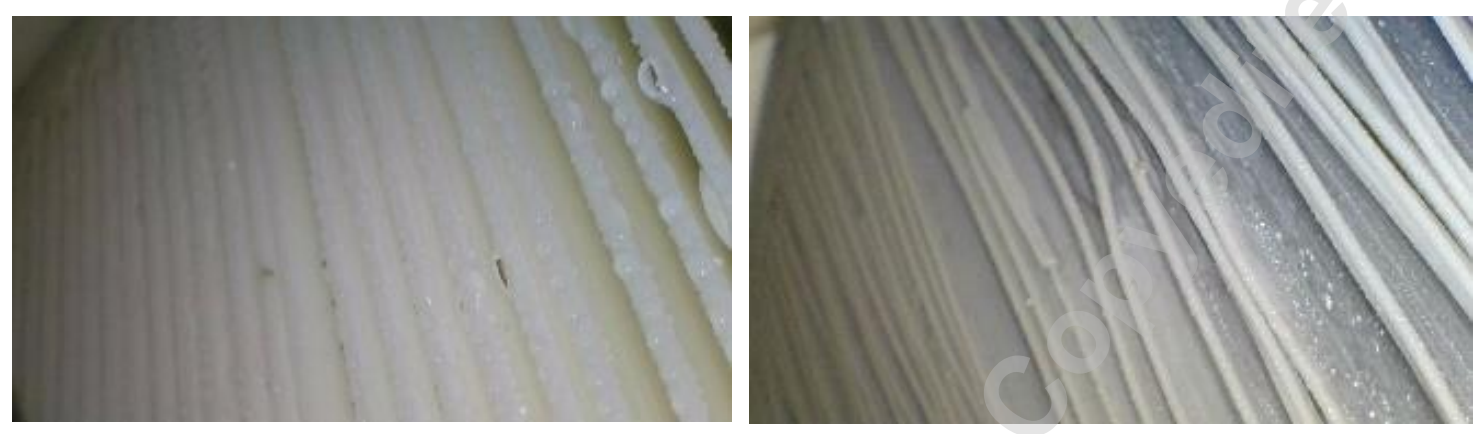

Fig. 13. Photo of droplet on the surface of parallel plate stack (left: TAC; right: reference system)

\section{ENERGY BALANCE CALCULATION}

The speaker has a Sound Pressure Level (SPL) of $83 \mathrm{~dB}$. At the distance of $75 \mathrm{~mm}$ away from the speaker, the SPL was estimated to be around $120 \mathrm{~dB}$. Therefore, the acoustic wave can generate about $1 \mathrm{~W}$ acoustic power at the stack position [27]. Furthermore, assuming that at the end of each experimental set, TAC reached a thermal equilibrium state, therefore the temperature gradient along the stack could be found. Considering that all Case- 0 can reach the maximum undamaged thermal gradient, the average values for different stack designs can be found in Table 10 .

Table 10 Final temperature gradient for different stack designs

\begin{tabular}{ccc}
\hline$\#$ & Final temperature gradient (K) & Average (K) \\
\hline P0 & 18.2 & 18.2 \\
\hline P1 & 15.0 & \\
P2 & 16.1 & 15.3 \\
P3 & 15.8 & \\
P4 & 14.5 & 14.3 \\
\hline S0 & 14.3 & \\
\hline S1 & 10.7 & 11.4 \\
S2 & 11.9 & \\
S3 & 11.6 & 16.2 \\
S4 & 11.5 & 15.4 \\
\hline C0 & 16.2 & \\
\hline C1 & 15.4 &
\end{tabular}




$\begin{array}{ll}\mathrm{C} 2 & 15.5 \\ \mathrm{C} 3 & 15.7 \\ \mathrm{C} 4 & 14.9\end{array}$

Therefore, the heat flow across the stack can be calculated using the Fourier's Law [28]:

$$
q=-k A \frac{\Delta \mathrm{T}}{L}
$$

where $\mathrm{A}$ is the cross-sectional area of stack, $\mathrm{k}$ is the thermal conductivity of PLA, $\mathrm{L}$ is the length of stack and $\Delta \mathrm{T}$ is the final temperature gradient.

Table 11 Heat flow and damage from condensation

\begin{tabular}{cccc}
\hline Stack & $\begin{array}{c}\text { Zeroth case } \\
\text { heat flow (W) }\end{array}$ & $\begin{array}{c}\text { Cases 1-4 } \\
\text { heat flow (W) }\end{array}$ & $\begin{array}{c}\text { Heat flow \% } \\
\text { reduction for } \\
\text { cases 1-4 }\end{array}$ \\
\hline Parallel plates & 0.14 & 0.12 & 15.48 \\
Squared mesh & 0.11 & 0.09 & 19.80 \\
Circular plates & 0.14 & 0.13 & 5.31 \\
\hline
\end{tabular}

Furthermore, we can also calculate the percentage reduction of heat flow as a measure to evaluate the damage caused by condensation and continuous vapor feeding, detailed calculation results can be found in Table 11 . Apparently, the circular stack had the lowest heat flow reduction, therefore it can also be concluded that the circular plates stack had the best performance in terms of preventing the damage to the TA cooling effect, and the result was consistent with the findings in Figs. 9-11 and Table 9.

\section{CONCLUSION}

In this study, the TAC was built and the water-saturated air was chosen as the working fluid, so that the low temperature caused by the TA effect can condense the water vapor and extract water from the air. Some conclusions can be made as follows:

1) The TAC using unpressurized humid air as the working fluid is a feasible approach, and it can achieve a good temperature drop at the cold end.

2) TA phenomena can enhance the condensation rate and thus improve dehumidification performance due to the low temperature zone in the stack.

3) Continuous vapor feeding and water harvesting via condensation actually will damage the TA effect and cause reduction in cooling capacity.

4) The stack's design directly affects the TA performance and condensation rate. Even though the parallel plate stack demonstrated the best thermoacoustic performance and cooling efficiency, circular stack had a better resistance to the damage caused by condensation. 
5) The stack in the TAC had dropwise condensation while the stack in the reference system was filmwise condensation. Therefore, the TAC can collect more water than the reference system.

6) Depending on the relative humidity level and temperatures, the stack design should be carefully selected to balance between the maximum cooling performance and the sustainability of thermoacoustic effect.

The potential application of this investigation can be an autonomous thermoacoustic water harvesting system in humid areas, if a TAE can be integrated with the TAC so that solar energy can be used to generate the sound wave.

\section{ACKNOWLEDGMENTS}

The authors appreciate the graduate research assistant scholarship provided by the College of Engineering and Computer Science at The University of Texas Rio Grande Valley.

\section{NOMENCLATURE}

\begin{tabular}{|c|l|}
\hline $0.5 \lambda$ & Acoustic half-wavelength \\
\hline$M$ & Acoustic Mach number \\
\hline$f$ & Acoustic operating frequency \\
\hline$W_{n}$ & Acoustic power \\
\hline$p_{A}$ & Acoustic pressure \\
\hline$\lambda$ & Acoustic wavelength \\
\hline$\rho_{\text {air }}$ & Air density \\
\hline$\mu_{\text {air }}$ & Air dynamic viscosity \\
\hline$\gamma_{\text {air }}$ & Air heat capacity ratio \\
\hline$\omega_{\text {wave }}$ & Angular velocity of sound wave \\
\hline COP & Coefficient of performance \\
\hline$T_{c}$ & Cold end temperature \\
\hline$D$ & Drive ratio \\
\hline$y_{0}$ & Half-spacing between parallel plates in the stack \\
\hline$T_{h}$ & Hot end temperature \\
\hline$C_{p_{\text {air }}}$ & Isobaric specific heat capacity of air \\
\hline$C_{v_{\text {air }}}$ & Isochoric specific heat capacity of air \\
\hline$\Lambda$ & Lambda correlation for COP calculations \\
\hline$p_{m}$ & Mean pressure \\
\hline$T_{m}$ & Mean temperature along the stack \\
\hline$Q_{n}$ & Normalized heat flow \\
\hline$L_{\text {stack }}$ & Normalized stack's length \\
\hline & \\
\hline
\end{tabular}




\begin{tabular}{|c|l|}
\hline$x_{\text {stack }_{n}}$ & Normalized stack's position \\
\hline$\Delta T_{m_{n}}$ & Normalized temperature difference \\
\hline$\delta_{k_{n}}$ & Normalized thermal penetration depth \\
\hline PLA & Polylactic acid, thermoplastic filament for 3D printing \\
\hline$B_{\text {stack }}$ & Porosity of the stack \\
\hline$\sigma$ & Prandtl number \\
\hline RH & Relative Humidity \\
\hline$s s_{\text {stack }}$ & Spacing between parallel plates in the stack \\
\hline$a_{\text {air }}$ & Speed of air \\
\hline$L_{s}$ & Stack's length \\
\hline$x_{\text {stack }}$ & Stack's position \\
\hline SPL & Sound Pressure Level \\
\hline$\Delta T_{m}$ & Temperature difference between hot and cold ends \\
\hline$k_{\text {air }}$ & Thermal conductivity of air \\
\hline$k_{P L A}$ & Thermal conductivity of PLA \\
\hline$\delta_{k}$ & Thermal penetration depth \\
\hline TA & Thermoacoustic \\
\hline TAR & Thermoacoustic refrigerator \\
\hline TAC & Thermoacoustic cooler \\
\hline$t_{\text {plate }}$ & Thickness of a single plate \\
\hline$\delta_{v}$ & Viscous penetration depth \\
\hline & \\
\hline
\end{tabular}

\section{REFERENCES}

[1] Dhuchakallaya, I., \& Saechan, P. (2017). Design and Experimental Study of a Cascade Thermoacoustic Engine for Remote and Rural Communities. Journal of Energy Resources Technology, 139(3), 032004.

[2] Tasnim, S. H. (2017). An experimental study on heterogeneous porous stacks in a Thermoacoustic Heat Pump. Journal of Energy Resources Technology, 139(4), 042005.

[3] Buliński, Z., Szczygieł, I., Kabaj, A., Krysiński, T., Gładysz, P., Czarnowska, L., \& Stanek, W. (2018). Performance analysis of the small-scale $\alpha$-type Stirling engine using computational fluid dynamics tools. Journal of Energy Resources Technology, 140(3), 032001.

[4] Swift, G. W. (1988). Thermoacoustic engines. The Journal of the Acoustical Society of America, 84(4), 1145-1180.

[5] Hou, M., Wu, Z., Yu, G., Hu, J., \& Luo, E. (2018). A thermoacoustic Stirling electrical generator for cold exergy recovery of liquefied nature gas. Applied Energy, 226, 389-396.

[6] Bennett, G. A. (1992). Analytical Approach to Selecting and Designing a Miniature Downhole Refrigerator. Journal of Energy Resources Technology, 114(4), 339-344. 
[7] Zolpakar, N. A., Mohd-Ghazali, N., Ahmad, R., \& Maré, T. (2017). Performance of a 3D-printed stack in a standing wave thermoacoustic refrigerator. Energy Procedia, 105, 1382-1387.

[8] Ajith Krishnan, R., \& Sandeep, V. S. Study on A Standing Wave Thermoacoustic Refrigerator Made of Readily Available Materials. International Journal of Scientific and Research Publications, 183.

[9] Tu, Y., Wang, R., Zhang, Y., \& Wang, J. (2018). Progress and expectation of atmospheric water harvesting. Joule, 2(8), 1452-1475.

[10] Malik, F. T., Clement, R. M., Gethin, D. T., Krawszik, W., \& Parker, A. R. (2014). Nature's moisture harvesters: a comparative review. Bioinspiration \& biomimetics, 9(3), 031002.

[11] Shi, W., Anderson, M. J., Tulkoff, J. B., Kennedy, B. S., \& Boreyko, J. B. (2018). Fog harvesting with harps. ACS applied materials \& interfaces, 10(14), 11979-11986.

[12] Tian, Y., Zhu, P., Tang, X., Zhou, C., Wang, J., Kong, T., Xu, M. \& Wang, L. (2017). Large-scale water collection of bioinspired cavity-microfibers. Nature communications, 8(1), 1080.

[13] Kim, H., Yang, S., Rao, S. R., Narayanan, S., Kapustin, E. A., Furukawa, H., Umans, A.S., Yaghi, O.M. \& Wang, E. N. (2017). Water harvesting from air with metal-organic frameworks powered by natural sunlight. Science, 356(6336), 430-434.

[14] Wang, J. Y., Liu, J. Y., Wang, R. Z., \& Wang, L. W. (2017). Experimental research of composite solid sorbents for fresh water production driven by solar energy. Applied Thermal Engineering, 121, 941-950.

[15] Fathieh, F., Kalmutzki, M. J., Kapustin, E. A., Waller, P. J., Yang, J., \& Yaghi, O. M. (2018). Practical water production from desert air. Science advances, 4(6), eaat3198.

[16] Kang, H., Zhou, G., \& Li, Q. (2010). Thermoacoustic effect of traveling-standing wave. Cryogenics, 50(8), 450458.

[17] Tasnim, S. H., Mahmud, S., \& Fraser, R. A. (2012). Effects of variation in working fluids and operating conditions on the performance of a thermoacoustic refrigerator. International Communications in Heat and Mass Transfer, 39(6), $762-768$.

[18] Zimmerman, O. T., \& Lavine, I. (1964). Psychrometric Tables and Charts, Industrial Research Service. Inc. Dover, New Hampshire.

[19] Hiller, R. A., \& Swift, G. W. (2000). Condensation in a steady-flow thermoacoustic refrigerator. The Journal of the Acoustical Society of America, 108(4), 1521-1527.

[20] Tijani, M. E. H., Zeegers, J. C. H., \& De Waele, A. T. A. M. (2002). Construction and performance of a thermoacoustic refrigerator. Cryogenics, 42(1), 59-66.

[21] Babaei, H., \& Siddiqui, K. (2008). Design and optimization of thermoacoustic devices. Energy Conversion and Management, 49(12), 3585-3598.

[22] Jin, T., Huang, J., Feng, Y., Yang, R., Tang, K., \& Radebaugh, R. (2015). Thermoacoustic prime movers and refrigerators: Thermally powered engines without moving components. Energy, 93, 828-853.

[23] Roger Legg. (2017). Chapter 1 - Properties of Humid Air. Air Conditioning System Design. ButterworthHeinemann, 1-28. 
[24] Engineering ToolBox. (2004). Density of Moist Humid Air. https://www.engineeringtoolbox.com/density-aird_680.html [Accessed on 12 Feb 2019]

[25] Wheatley, J., Hofler, T., Swift, G. W., \& Migliori, A. (1985). Understanding some simple phenomena in thermoacoustics with applications to acoustical heat engines. American journal of physics, 53(2), 147-162.

[26] Tang, K., Huang, Z. J., Jin, T., \& Chen, G. B. (2009). Influence of acoustic pressure amplifier dimensions on the performance of a standing-wave thermoacoustic system. Applied Thermal Engineering, 29(5-6), 950-956.

[27] Soundpower calculator. [Accessed on Feb 25, 2019]. http://www.sengpielaudio.com/calculator-soundpower.html

[28] Bird, B. R., Stewart, W. E., Lightfoot, E. N. (2007), Transport Phenomena (2nd Ed.). John Wiley \& Sons, Inc., p. 266, ISBN 978-0-470-11539-8. 